\title{
Natural and human induced factors influencing the abundance of Schistosoma host snails in Zambia
}

\author{
Concillia Monde • Stephen Syampungani • Paul J. van den Brink
}

Received: 17 September 2015 / Accepted: 5 May 2016/Published online: 26 May 2016

(C) The Author(s) 2016. This article is published with open access at Springerlink.com

\begin{abstract}
Schistosomiasis remains a global public health problem affecting about 240 million people. In Zambia, 2 million are infected while 3 million live with the risk of getting infected. Research and interventions relating to schistosomiasis are mainly linked to disease epidemiology. Malacological and ecological aspects of the disease are superficially understood. Developing effective control measures requires an understanding of interacting environmental and socioeconomic factors of host snails vis-a-vis schistosomiasis. Therefore, the present work involved collecting social and environmental data in a large field study in two zones in Zambia that are different in terms of temperature and rainfall amounts. Social data collected through questionnaires
\end{abstract}

Electronic supplementary material The online version of this article (doi:10.1007/s10661-016-5351-y) contains supplementary material, which is available to authorized users.

C. Monde · P. J. van den Brink

Department of Aquatic Ecology and Water Quality Management, Wageningen University and Research Centre, P.O. Box 47, 6700 AA Wageningen, The Netherlands

C. Monde $(\bowtie)$

Department of Zoology and Aquatic Sciences, Copperbelt University, P.O. Box 21692, Jambo DriveRiversideKitwe, Zambia e-mail: concillia.monde@wur.nl

S. Syampungani

Department of Plant and Environmental Sciences, Copperbelt University, P.O Box 21692, Jambo DriveRiversideKitwe, Zambia

P. J. van den Brink

Alterra, Wageningen University and Research Centre, P.O. Box 47, 6700 AA Wageningen, The Netherlands included demographic, educational and knowledge of schistosomiasis disease dynamics. Environmental data included physicochemical factors, aquatic plants and snails. Gender $(P<0.001)$ significantly influences livelihood strategies, while age $(P=0.069)$ and level of education $(P=0.086)$ have a moderate influence in zone I. In zone III, none of these factors (age, $P=0.378$; gender, $P=0.311$; education, $P=0.553$ ) play a significant role. Environmental parameters explained 43 and $41 \%$ variation in species composition for zones I and III, respectively. Most respondents' (52\%, $87 \%$ ) perception is that there are more cases of bilharzia in hot season than in other seasons (rainy season $23 \%, 7 \%$; cold season $8 \%, 0 \%$ and year round $17 \%, 6 \%$ ) for zone I and zone III, respectively.

Keywords Schistosomiasis $\cdot$ Host snails · Epidemiology $\cdot$ Malacological

\section{Introduction}

Schistosomiasis remains a global health problem in the twenty-first century with an estimated 240 million people in 74 countries infected, of whom $90 \%$ are living in sub-Saharan Africa (Sady et al. 2013). The parasites responsible for schistosomiasis affecting humans belong to the genus Schistosoma and are dependent on susceptible water snails for their asexual life stages (Boelee and Madsen 2006). Humans are the primary hosts, and transmission between the two hosts takes place in contaminated water (Ojewole 2004). Schistosomiasis is 
subject to environmental perturbations such as climatic, ecological, hydrological and socioeconomic factors (Michael et al. 2010). As such, the management of schistosomiasis transmission requires an understanding of these interacting factors (Monde et al. 2015). Currently, advanced methodologies for predicting and mapping the prevalences of disease are increasingly being used (Ahmad et al. 2015). For schistosomiasis, GIS and remote sensing techniques have been applied in different parts of the world including China (Zhang et al. 2013; Zhou et al. 2001) and some African countries (Simoonga et al. 2009). These techniques model disease prevalence based on temperature and vegetation data of the target area (Kristensen et al. 2001). While they provide a convenient way to map large-scale (up to $50 \mathrm{~km}$ radius; Brooker 2007) environmental preferences of host snails, they do not model small-scale local environmental factors such as demographic, educational and socioeconomic aspects of affected communities which are significant in transmission dynamics of schistosomiasis (Simoonga et al. 2009). Several survey-based studies indicate strong correlation between socioeconomic factors and prevalence of schistosomiasis in the Americas, Asia, (Gazzinelli et al. 2006; Ximenes et al. 2003; Yi-Xin and Manderson 2005) and Africa (Chandiwana and Woolhouse 1991; Kapito-Tembo et al. 2009). Similarly, many studies link environmental (physical, chemical and biological) characteristics of the aquatic body to presence of Schistosoma host snails (Giovanelli et al. 2005a; Ndifon and Ukoli 1989). Environmental factors affect the Schistosoma host snails' ability to utilize the habitat and herewith their survival and reproductive potential (Domenici et al. 2007). This link to ecosystem conditions for host-parasite interactions (Patz et al. 2000) is what results in heterogeneities in abundance at local environmental level. Changes in these conditions, whether natural or human mediated, influence the population dynamics of parasites and their hosts and hence epidemiological aspects of the diseases they cause (Patz et al. 2000; Vora 2008). The heterogeneous and complex nature of these interacting factors (Ojewole 2004; WHO 1998) partly explain why schistosomiasis is still a global public health problem especially in Sub-Saharan African countries like Zambia (Chitsulo et al. 2000).

Like many tropical countries, Zambia has struggled with schistosomiasis for several decades. Out of a population of about 13 million, 2 million are said to be infected with schistosomiasis while 3 million are living in constant threat of infection (ZBCP 2009). In some rural communities, infection rate is as high as $90 \%$ of the population (ZBCP 2009). Knowledge on the prevalence of schistosomiasis in Zambia dates back to 1855 (nineteenth century) during David Livingstone's excursions (Michelson 1989), but the problem remains unabated in the twenty-first century. Among other challenges, the lack of research on the ecological aspects of schistosomiasis exacerbates the problem (Monde et al. 2015). Historic and current research and interventions relating to schistosomiasis are mainly linked to the epidemiology of the disease (Agnew-Blais et al. 2010; Michelson 1989; Strahan et al. 2012). Malacological and ecological aspects of schistosomiasis are superficially understood, and no snail control interventions have been attempted in Zambia (Siziya and Mushanga 1996). This may be attributed to lack of information on the influence of environmental and socioeconomic factors on the population dynamics of Bulinus globosus and Biomphalaria pfeifferi vis-à-vis schistosomiasis. Developing an understanding of the influence of environmental and socioeconomic factors on the population dynamics of these host snails vis-à-vis schistosomiasis would greatly contribute towards its control.

Therefore, we examined the influence of environmental and socioeconomic factors on the population dynamics of the host snails vis-à-vis schistosomiasis. We evaluated the following:

1. How the behavioural traits of adjacent local human communities are associated with Schistosoma infections

2. How habitat factors affect populations of host snails

3. How seasonal variations influence host snail abundance

\section{Materials and methods}

\section{Description of the study sites}

The study was conducted in two ecologically distinct zones in Zambia: zone I (Sinazongwe, Siavonga) and zone III (Solwezi, Mufumbwe, Zambezi) (Fig. 1). The two zones receive different amounts of rainfall; zone I receives less than $700 \mathrm{~mm}$ while zone III receives between 1000 and $1500 \mathrm{~mm}$ annually (MAFF 2001). Zone I is prone to drought, and temperature ranges between 
Fig. 1 Ecological zones and study sites

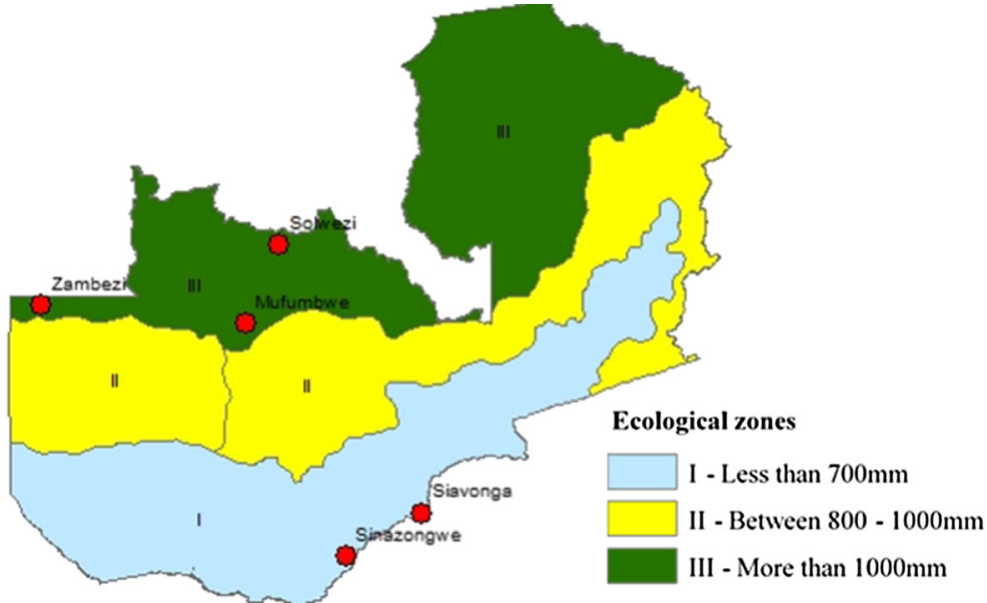

10 and $37^{\circ} \mathrm{C}$. Snail habitat is mainly concentrated in seasonal pools and tributaries of large water systems like Kafue, Zambezi and Kariba systems. Zone III on the other hand is a bit cooler with temperatures ranging between 6 and $32{ }^{\circ} \mathrm{C}$. It is a high rainfall area and has many perennial water systems. Subsistence agriculture (Ndambo 2005) and fishing (Mudenda et al. 2005) are the major livelihood strategies in the study areas. In zone I, small-scale farming (maize) and animal husbandry predominate while small scale-farming (cassava) and fishing are the dominant activities in zone III. Vegetable gardening is an off-season activity common to both zones.

\section{Experimental design}

Data collection was divided into two parts, namely, questionnaire survey and environmental data collection. Each of these surveys was designed differently.

\section{Questionnaire survey}

The questionnaire survey was designed to collect social data that may have an impact on schistosomiasis dynamics in the study areas. In our survey, all the members of the community who were aged 10 years and above were eligible to participate. The 10-year age cut-off point was thought to be adequate to ensure coherent responses. Verbal permission was sought from all participants or their guardians prior to administering the questionnaires. The questionnaire was pretested by administering it to ten randomly selected community members and adjustments made accordingly. The questionnaire was designed to extract information ranging from demographic (gender, age, livelihood strategy), to educational, to knowledge levels of schistosomiasis disease dynamics. These questionnaires were administered by the researcher and an assistant who served as translator in some cases. A total of 168 (zone I, $n=92$; zone III, $n=76$ ) people participated in this survey.

\section{Environmental data}

Sampling was done in rivers, streams and dams selected based on clinical records of prevalence of schistosomiasis in adjacent communities as advised by District Health officials (Pers Com.). Sample plots of $10 \mathrm{~m} \times 10 \mathrm{~m}$ were established in selected portions of rivers, streams, ox-bow lakes and reservoirs. Where the size of the water body did not allow for establishment of $10 \times 10 \mathrm{~m}$ plots, the length of the plot was maintained at $10 \mathrm{~m}$ while the width was up to the midpoint of the water body. Collection of water samples for determination of physicochemical parameters, estimation for macrophyte cover and snail surveys were done in these plots.

\section{Physicochemical properties}

Dissolved oxygen, $\mathrm{pH}$, conductivity, turbidity, temperature, nitrate, phosphate and calcium were measured bimonthly in situ from March 2013 to December 2013 using an AM-200 Aquaread GPS Aquameter. Water and sediment samples for ex situ metal analysis were collected into previously rinsed 500-ml polyethylene bottles with polyethylene caps. Each sample was preserved by adding concentrated nitric acid $\left(\mathrm{HNO}_{3}\right)$ to bring the $\mathrm{pH}$ to $2\left(1.5 \mathrm{ml} \mathrm{HNO}_{3}\right.$ to $500 \mathrm{ml}$ of sample water) and 
stored at room temperature. A weak acid extraction method (nitric acid-hydrochloric acid digestion) was used to analyse for metals in water and sediment samples (APHA 1995; Giddings et al. 2001). The flow velocity of water was measured by placing a floating object in the middle of the water body and recording the time taken to drift over a 10-m distance. The substratum was visually categorized as gravel, sandy or muddy at all sites.

\section{Aquatic plants}

All aquatic plants (macrophytes) were identified based on Cook (2004) and Gerber et al. (2004), while observation based on the established Likert scale of 0 to 5 was used to estimate percent cover of macrophytes over the area. For this scale, 0 indicated no macrophyte while 5 indicated $100 \%$ macrophyte cover. In order to ensure consistency, estimates of macrophyte cover were made by the same person throughout the study.

\section{Snails}

Two methods were used to collect live snails: by a gloved hand in shallow water and by using a scoop net where water depth could not permit collection by hand. The net was made of $2 \times 2-\mathrm{mm}$ mesh size kitchen sieve that was supported by a metal frame mounted on a $1.5-\mathrm{m}$ wooden handle. Search for snails by either way was conducted for $20 \mathrm{~min}$ at each site. The search team comprised the same persons all the time. All materials such as boulders, gravel and floating, submerged and emerging vegetation, were searched for snails. Contents of the scoop net were emptied into a tray where snails were identified based on their morphological features (Mandahl-Barth 1962) and counted.

\section{Data analysis}

Two sets of data were analysed, namely, those of the social survey and the environmental and biological data in each zone (zones I and III).

\section{Social survey data}

Questionnaire responses were coded and entered into SPSS (IBM SPSS Statistics for Windows, Version 22.0) software. Both descriptive and inferential statistics were performed. Descriptive statistics gave an overview of trends in livelihood strategies and water use patterns and were presented as frequencies and percentages. Inferential statistics were performed by multinomial logistic regression with gender, age and educational level as factors. Response variables were livelihood strategies, water use patterns and knowledge levels of disease dynamics.

\section{Environmental and biological data}

Partial redundancy analysis (RDA) was performed in order to identify factors with the most significant impact on the distribution of the snail community and their correlation. Physical factors including turbidity, colour of water, flow velocity and type of substrate and chemical factors such as $\mathrm{pH}$, nutrients (nitrates, phosphates), heavy metals (copper, cobalt, chromium, cadmium, lead, nickel) dissolved oxygen, oxygen reduction potential, total dissolved solids and electric conductivity were used as predictor variables for snail abundance and distribution. The significance of these factors in explaining the distribution of the snails was determined using permutation tests under the RDA option, using the sampling months as co-variables. A partial RDA was performed which only included the significant explanatory variables $(P<0.10)$ and the sampling months as covariables. Analyses were performed separately for the samples taken from zones I and III. The RDA analyses were performed with the Canoco version 5 program (Ter Braak and Šmilauer 2012).

To identify environmental factors (Table 1) that act as habitat filters which influence distribution and abundance of aquatic snails (including Schistosoma host snails) and to explore how these effects can be quantified, biological and physicochemical parameters were linked to observed densities of aquatic snails.

Identification of single variables and combinations of variables with high explanatory potential was achieved by use of a linear regression selection method using RSEARCH procedure in GenStat release 12.1 with sampling date as covariate (Payne 2007). For all variables, simple single linear regressions were performed with composition and log-transformed $(\operatorname{Ln}(x+1)$ abundance of snails as endpoints separately. Each variable was paired with each species (excluding species with very low abundances), and the variables with significant correlation coefficients were selected for forward multiple regression. Two levels of significance were adopted: (i) the $5 \%$ probability for type I error $(P \leq 0.05)$ and (ii) 
Table 1 Environmental variables monitored in the field for determination of possible impact on abundance and composition of freshwater snails in Zambia

\begin{tabular}{|c|c|c|}
\hline \multicolumn{2}{|c|}{ Explanatory variables } & \multirow{2}{*}{$\begin{array}{l}\text { Response variables } \\
\text { Molluscs }\end{array}$} \\
\hline $\begin{array}{l}\text { System } \\
\text { attribute }\end{array}$ & Habitat filter & \\
\hline $\begin{array}{l}\text { Chemical } \\
\text { properties }\end{array}$ & $\begin{array}{l}\mathrm{pH} \text {, nutrients } \\
\text { (nitrates, phosphates), } \\
\text { heavy metals } \\
\text { (Cu, Co, Cr, } \mathrm{Cd}, \mathrm{Pb} \text {, } \\
\text { Ni) }\end{array}$ & $\begin{array}{l}\text { Species of freshwater } \\
\text { molluscs } \\
\text { (composition and } \\
\text { abundance) }\end{array}$ \\
\hline $\begin{array}{l}\text { Physical } \\
\text { properties }\end{array}$ & $\begin{array}{l}\text { DO, ORP, TDS, EC } \\
\text { Turbidity, colour, flow }\end{array}$ & \\
\hline Substrate & $\begin{array}{l}\text { Gravel, sandy, muddy, } \\
\text { detritus }\end{array}$ & \\
\hline Ther & Temperature fluctuations & \\
\hline $\begin{array}{l}\text { Biological } \\
\text { regime }\end{array}$ & $\begin{array}{l}\text { Competitors, predators, } \\
\text { macrophytes }\end{array}$ & \\
\hline
\end{tabular}

the $10 \%$ accepted error probability $(0.05<P \leq 0.1)$ due to possible high levels of variation in sampling sites.

\section{Results}

\section{Water contact patterns}

Livelihood strategies are significantly $(P<0.001)$ influenced by gender in zone I but not in zone III (Fig. 2, Table 2). While more women tend to be small-scale farmers, men combine farming and fishing to sustain their families in zone I. Age $(P=0.069)$ and level of education $(P=0.086)$ have a moderate influence on the livelihood strategies in zone I. More people with primary education of ages between 20 and 30 years depend on
Table 2 Results of multinomial logistic regression analysis

\begin{tabular}{|c|c|c|c|}
\hline \multirow[t]{2}{*}{ Response variable } & \multirow{2}{*}{$\begin{array}{l}\text { Predictor } \\
\text { variables }\end{array}$} & \multicolumn{2}{|l|}{$P$ value } \\
\hline & & Zone I & Zone III \\
\hline \multirow[t]{3}{*}{ Livelihood strategy } & Age group & $0.069 * *$ & 0.378 \\
\hline & Gender & $<0.001^{*}$ & 0.311 \\
\hline & $\begin{array}{l}\text { Level of } \\
\text { education }\end{array}$ & $0.086^{* *}$ & 0.553 \\
\hline \multirow{3}{*}{$\begin{array}{l}\text { Pattern of river/stream/dam } \\
\text { water use }\end{array}$} & Age-group & 0.219 & $<0.001 *$ \\
\hline & Gender & $0.001^{*}$ & $0.013 *$ \\
\hline & $\begin{array}{l}\text { Level of } \\
\text { education }\end{array}$ & $0.079 * *$ & 0.538 \\
\hline \multirow{3}{*}{$\begin{array}{l}\text { Knowledge of problems } \\
\text { due to river/stream/dam } \\
\text { water use. }\end{array}$} & Age group & 0.442 & 0.185 \\
\hline & Gender & 0.632 & $0.075^{* *}$ \\
\hline & $\begin{array}{l}\text { Level of } \\
\text { education }\end{array}$ & $0.040^{*}$ & 0.357 \\
\hline
\end{tabular}

Significant $P$ values are indicated by an asterisk (*), moderately significant ones by two asterisks $(* *)$

farming for their livelihood instead of fishing. In zone III, however, none of these factors (age, $P=0.378$; gender, $P=0.311$; education, $P=0.553$ ) play a significant role.

Overall, subsistence farming is the main livelihood strategy in zones I and III. Fishing which is often the next option for rural communities is dominated by men relative to women in zone I and zone III (Fig. 2).

Bathing/swimming, gardening, washing and cassava soaking are the main avenues through which members of the study communities get in contact with water possibly contaminated with Schistosoma (Fig. 3). These patterns are gender dependant in both zones $(P \leq 0.001$, zone I; $P=0.013$, zone III) (Table 2). More women than men access water contact points during domestic chores like washing plates and clothes and soaking cassava for
Fig. 2 Livelihood strategies across gender in zone I (a) and zone III (b)
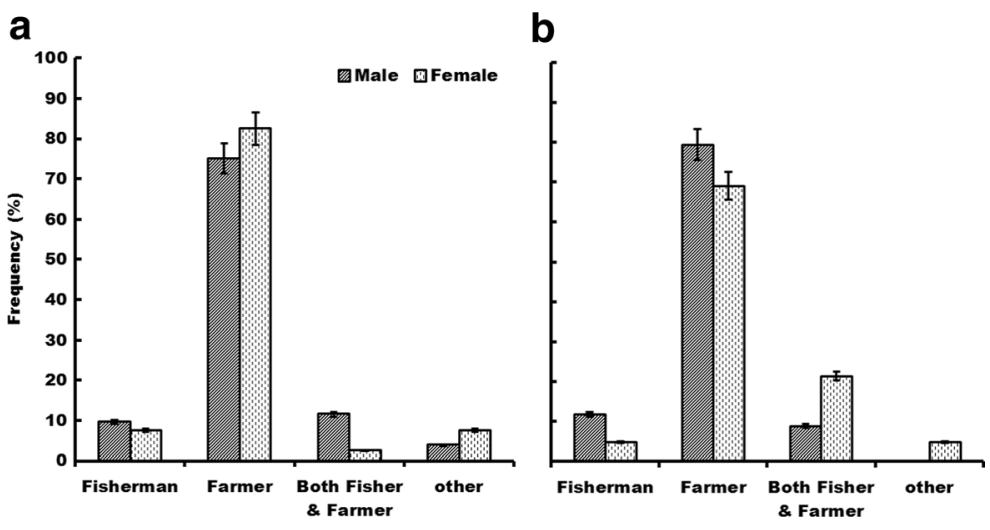
Fig. 3 Stream water use across gender in zone I (a) and zone III (b)
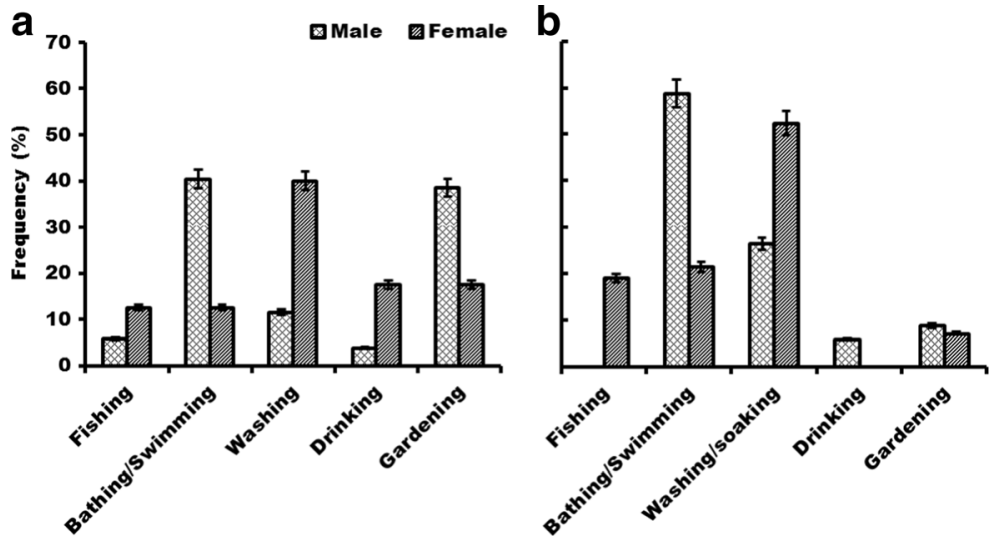

processing into cassava mill. On the other hand, more men than women are exposed through recreational activities such as bathing and swimming and occupational activities such as gardening (Fig. 3). Level of education moderately influences stream water use patterns in zone I with less educated people (primary level) having more contact with stream water. In zone III, age significantly affects how people get exposed to possibly Schistosoma-contaminated water (Table 2). Younger people (16-20) are more likely to get exposed through recreational activities and middle-aged people (26-30) through domestic chores.

Levels of education significantly influenced the knowledge about the Schistosoma problem resulting from use of water obtained from streams and dams in zone I (Table 2). Most respondents with some level of education (primary to tertiary) knew that contact with stream/dam water resulted in many health-related problems including schistosomiasis. In zone III, on the other hand, gender has a moderate influence on knowledge levels regarding schistosomiasis (Table 2). Females are comparatively more aware of waterborne diseases than are males. Overall, in zone I, most of the respondents associate bilharzia to contact with stream or dam water followed by diarrhoea, rush and malaria. Similarly, in zone III, contact with stream/dam water is associated by most people with bilharzia, followed by rush, diarrhoea, worms and malaria (Fig. 3). Season is perceived to influence the prevalence of schistosomiasis among the community members. Most of the respondents' (52\%, $87 \%$ ) perception is that the hot season has more cases of bilharzia in the communities than in all other seasons (rainy season $23 \%, 7 \%$; cold season $8 \%, 0 \%$ and year round $17 \%, 6 \%$ ) for zone I and zone III, respectively.
Environmental parameters and snail abundance

Five snail species were collected during four repetitive sampling events in both zones I and III: four from class pulmonata (Lymnaea natalensis, B. globosus, B. pfeifferi, Physa acuta) and one from class prosobranchia (Melanoides tuberculata). Three (i.e. L. natalensis, B. globosus, B. pfeifferi) of the four pulmonate snail species are of medical and veterinary importance. In both zones, M. tuberculata showed the highest density of $93 \%$ in zone I and $42 \%$ in zone III over the whole period, though with a somewhat erratic distribution over the samples especially in zone I (Fig. 4).

In zone I, L. natalensis accounted for $4 \%$ with the highest numbers recorded at the onset of the hot dry season and declining markedly towards the end of the season. B. globosus accounted for $2 \%$ while B. pfeifferi accounted for $1 \%$ (Fig. 4). $P$. acuta was the least abundant with $n=1$. The pulmonates $B$. globosus and $L$. natalensis generally showed a similar trend with peaks during the hot dry season (August to November). B. pfeifferi was abundant during the hot months of the year.

In zone III, $M$. tuberculata was followed by B. globosus with $37 \%$. P. acuta was the least abundant with $n=1$, while $B$. pfeifferi and $L$. natalensis accounted for 3 and $18 \%$, respectively. The pulmonates B. globosus and B. pfeifferi showed a similar trend with peaks during the hot dry season (August to November). Prosobranch M. tuberculata on the other hand was present in sufficient numbers during four sampling events but peaked in the cool dry season (April to August) in both zones (Fig. 5). 
Fig. 4 Participants' perceived problems associated with contact with contaminated water in zone I (a) and zone III (b)
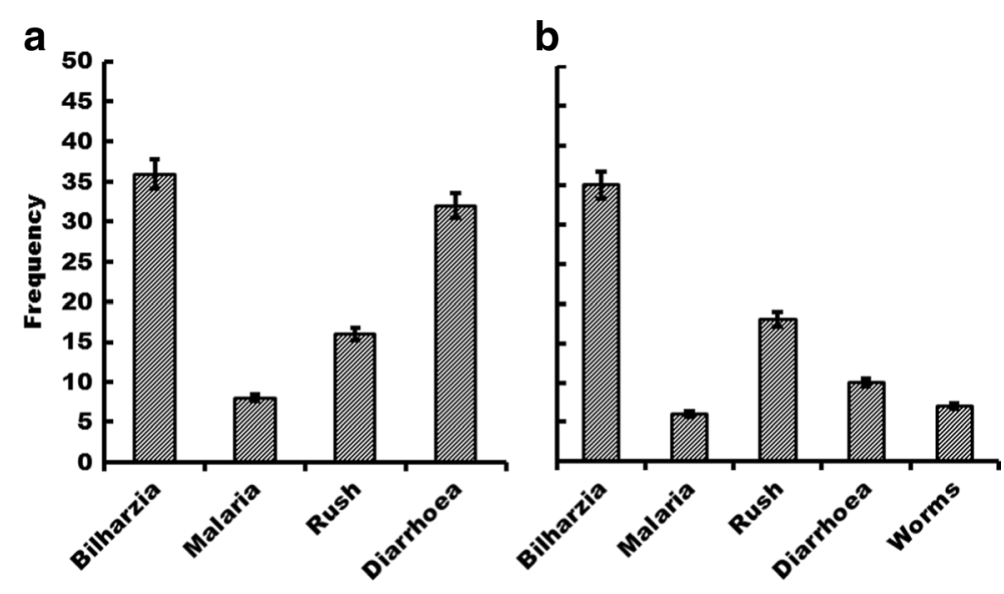

\section{Redundancy analysis}

The results presented in the RDA biplot (Fig. 6) show that all pulmonate snails recorded are positively correlated with gravel as a substrate and flow velocity in zone I. Prosobranch $M$. tuberculata is positively correlated with clear water and negatively correlated with cloudy water, electric conductivity (EC), total dissolved solids (TDS) and nitrates. P. acuta was only found once in both zones, while in zone III, the results show marked variability in habitat selection by the pulmonate snails recorded. B. globosus is positively correlated with sandy substrate, ORP and turbid water while B. pfeifferi is positively correlated with flow velocity, macrophytes and cobalt. M. tuberculata is positively correlated with EC, TDS and to a lesser extent calcium (Fig. 6).

\section{Linear regression}

Table 3 gives results of the single linear regressions between environmental parameters and snail populations for zones I and III. Parameters with significant
$(P \leq 0.05)$ correlations were selected for multiple regression analysis in order to come up with factor combinations with the best explanatory power for the distribution and abundance of snails. The positive $(+)$ and negative $(-)$ signs beside the Adj $R^{2}$ values represent the direction of relationship.

\section{Multiple regression (factor combinations)}

For zone I, seven significant combinations of two parameters were found for $B$. globosus. The combination with the highest explanatory potential was that of metal content (Cd-W) and flow velocity explaining $38 \%$ (Adj $R^{2}$ ) of the variance in the population dynamics of $B$. globosus, followed by another two-way combination of flow velocity and chlorophyll content explaining $32 \%$ (Adj $R^{2}$ ) of the variance. For B. Pfeifferi, 17 combinations were found: ten two-way and seven three-way. The highest variance (Adj $R^{2}=41 \%$ ) was explained by a three-way combination of flow velocity and two metals $(\mathrm{Co}-\mathrm{S}$ and $\mathrm{Pb}-\mathrm{W})$. Metal content in combination with other factors including type of substrate and levels of
Fig. 5 Total number of snails collected over time in zone I (a) and zone III (b). NB: P. acuta not included in the diagram as it was only found once
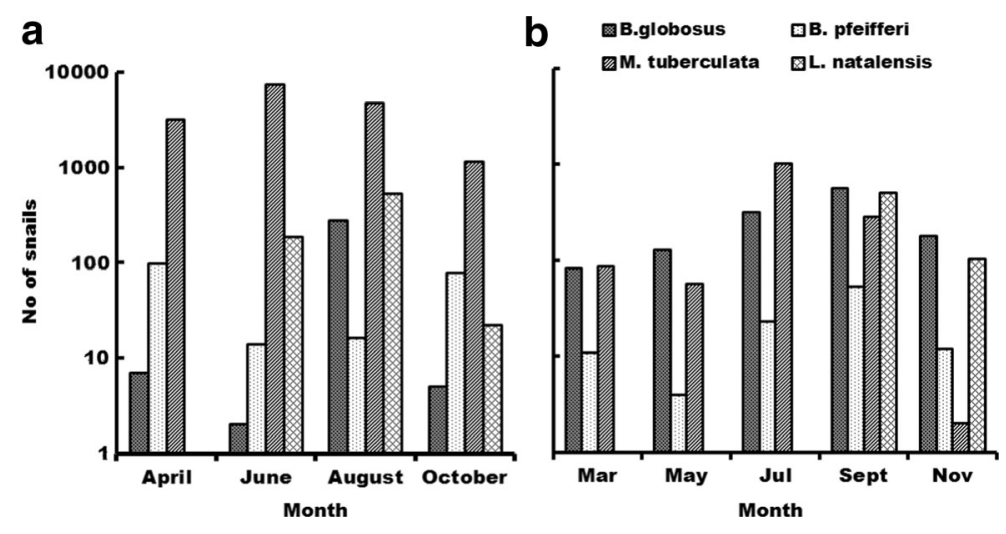


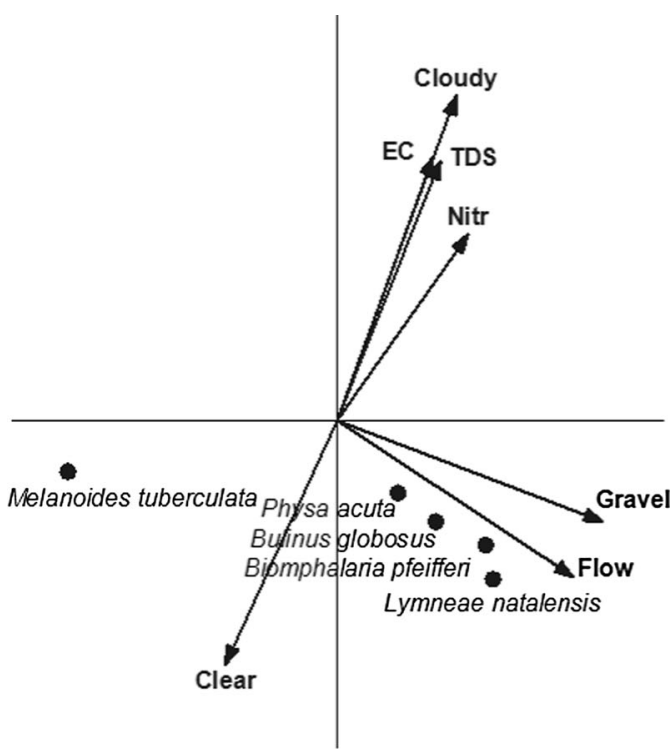

Zone I

Fig. 6 Partial RDA biplot showing snail species found in the study sites and their correlation with environmental parameters of zone I and zone III. For zone I, the explanatory variables explained $43 \%$ of the variation in species composition, while the first and second axes display 82 and $14 \%$ of this variation, respectively. For zone III, the explanatory variables explained

dissolved oxygen explain an amount of variance ranging from 32 to $39 \%$. For M. tuberculata, 12 factor combinations were found: eight two-way and four three-way. The three-way factor combination of condition of water (cloudy) flow velocity and type of substrate (gravel) explain $39 \%\left(\operatorname{Adj} R^{2}\right)$ of the variance, while a twoway combination of flow velocity and condition of water (cloudy) explain $33 \%$ (Adj $R^{2}$ ) of the variance. In case of $L$. natalensis, nine combinations were possible: seven two-way and two three-way combinations. The highest variance $32 \%\left(\operatorname{Adj} R^{2}\right)$ was obtained from a two-way factor combination of metal content $(\mathrm{Cd}-\mathrm{W})$ and flow velocity. The highest three-way combination (Adj $R^{2}=30 \%$ ) was that of chlorophyll-a, flow velocity and type of substrate (gravel).

For zone III, nine factor combinations were found for B. globosus. Of these, seven were two-way and two were three-way combinations. The highest explanatory potential was from a three-way combination of condition of water (cloudy), oxygen reduction potential (ORP) and type of substrate (gravel) explaining $28 \%$ (Adj $R^{2}$ ) of the variance in the population dynamics of B. globosus. The second best combination with explanatory potential of $25 \%\left(\operatorname{Adj} R^{2}\right)$ of the variance was a two-way combination of condition of water (cloudy)

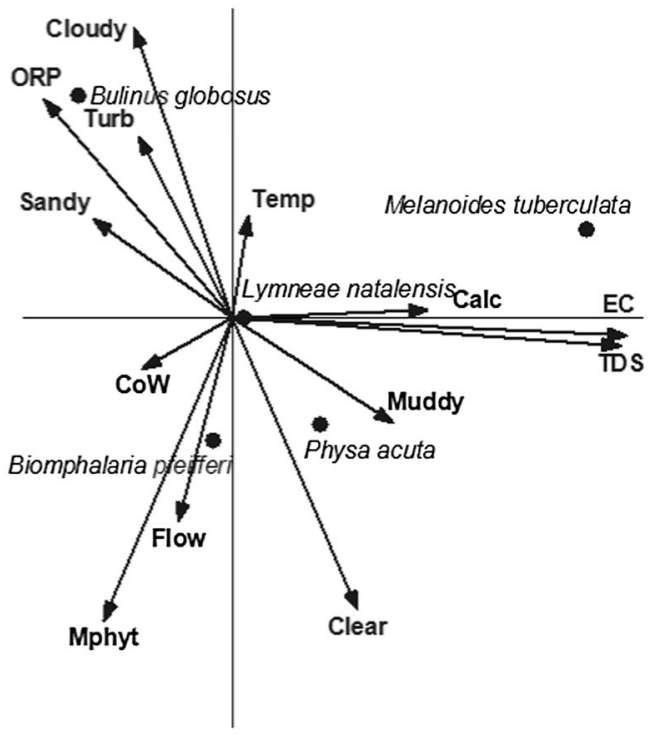

Zone III

$41 \%$ of the variation in species composition, while the first and second axes display 52 and $21 \%$ of this variation, respectively. Key: Nitr nitrates, $E C$ electric conductivity, TDS total dissolved solids, $C o W$ cobalt in water, $C$ alc calcium, ORP oxygen reduction potential, Temp temperature, Turb turbidity, MPhyt macrophytes

and ORP. For B. pfeifferi, eight combinations were found: six two-way and two three-way. Similarly, the highest variance $\operatorname{Adj} R^{2}=28.4$ was explained by a threeway combination of flow velocity, metal content $(\mathrm{Co})$ and type of substrate (muddy). For M. tuberculata and L. natalensis, only two-way combinations were observed to have significant explanatory potential. Electric conductivity and macrophytes explain $43 \%\left(\right.$ Adj $\left.R^{2}\right)$ while metal (Co) content and turbidity explain $50 \%$ (Adj $R^{2}$ ) of the variance in $M$. tuberculata and $L$. natalensis, respectively.

\section{Discussion}

Water contact patterns

The exposure patterns to Schistosoma infection in the study sites include those through domestic, recreational and occupational activities (Figs. 2 and 3). Such exposure patterns were also observed by various researchers in other parts of the world (Fenwick et al. 2006; King and Dangerfield-Cha 2008). However, heterogeneities occur at smaller units such as village groupings and have important implications to the transmission 
Table 3 Results of single linear regression where each habitat factor is regressed against each snail species showing $P$ values and adjusted $R^{2}$ for zones I and III

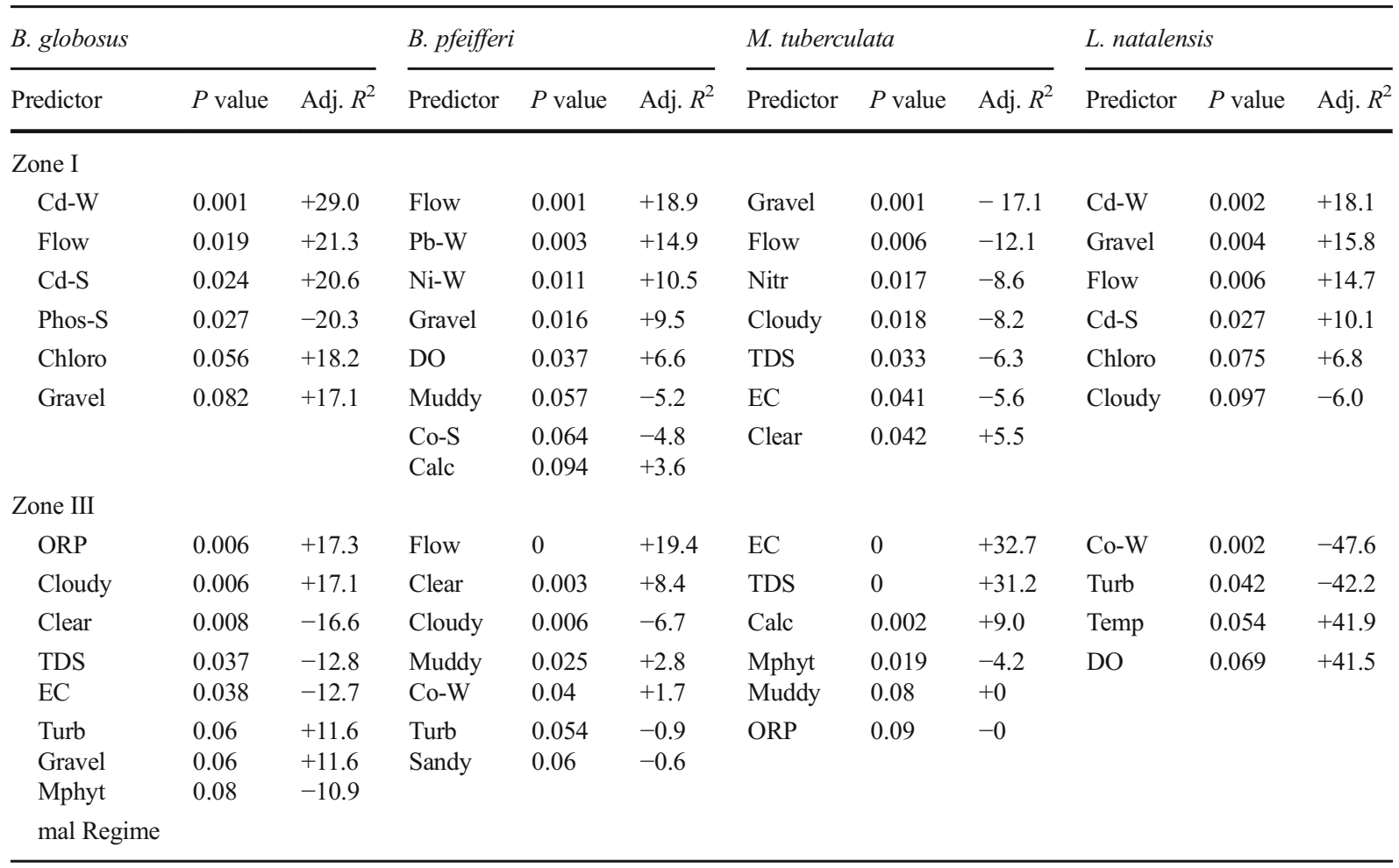

Cloudy, clear, turb condition of water, Gravel, muddy, sandy substrate type, $M p h y t$ macrophytes, $C o-W, P b-W, N i-W$ metals in water, $C d-S$, Co-S metals in sediment, Flow flow velocity, Nitr nitrates, Phos phosphates, Chloro clorophyll-a

dynamics of schistosomiasis. In Kenya (Satayathum et al. 2006) and China (Liang et al. 2007), differences in infection risks and rates were observed within climatologically homogeneous regions. This heterogeneity was attributed to differences in land use, age and gender structure and kinship at the village level (Satayathum et al. 2006). Our study also confirms the existence of differences in potential transmission pathways based on gender, age and level of education (Table 2). The influence of gender on water use patterns was found to be significant in both zone I and zone III, with the differences being the same for the bathing/swimming and washing activities, but not for the others (Fig. 3). In both zones, recreation activities of bathing and swimming are important exposure pathways for males, while for females, domestic chores including washing of clothes and utensils and soaking of cassava expose them to contaminated water. Similarly, the role of gender in exposure patterns was also reported in Malawi with boys having a higher infection rate than girls due to exposure through swimming and bathing (Kapito-
Tembo et al. 2009), in Senegal where females spent more frequent and longer times exposed to contaminated water than males through domestic chores (Sow et al. 2011) and in Zimbabwe with males having higher exposure through recreation activities than women (Chandiwana and Woolhouse 1991). Age is another important factor influencing exposure patterns. In this study, the effect of age on exposure was significant $(P<0.001)$ in zone III but not in zone I. Adolescents and young adults (16-25 years) are more likely to swim and/or bath in streams and other open water areas while older people get exposed through domestic and occupational activities. Similarly in Brazil, Gazzinelli et al. (2006) found a positive correlation between age and prevalence of schistosomiasis, and adolescents and young adults (15-29 years) were most affected. Education is an important tool which governs individual behaviour. In this study, education had a significant $(P=0.040)$ positive correlation with knowledge levels of schistosomiasis in zone I but not in zone III. Educated people are more likely to avoid behaviours that put them 
at risk of infection. Yang et al. (2015) concluded that "at the individual level, information, education and communication is an essential measure to decrease human exposure to water potentially containing cercariae". The significant impact of education in zone I can be attributed to the work of the Zambia Bilharzia Control Programme (ZBCP) which has prioritized two provinces (southern and eastern provinces). Although the ZBCP's main focus is on acquiring and correctly administering praziquantel, health education using information, education and communication materials is an important element of the programme (Kabatereine et al. 2006). These differences in factors influencing exposure patterns in this study confirm the heterogeneous nature of disease patterns which may also reflect the cultural differences among communities (Huang and Manderson 1992). In zone I, for instance, where cattle is a major part of the culture, cattle herding is a risk factor as it involves wading in potentially infested water and is a male activity. This claim is in agreement with Yi-Xin and Manderson (2005) who observed that livestock breeding increases human-water contact activities when they allow their animals to graze near water. In zone III, on the other hand, soaking of cassava for processing into cassava powder, a staple food, involves exposure to potential transmission sites over a considerable time for females. These cultural differences could model the risk of disease in a community between genders.

Environmental parameters and snail abundance

From the analysis of habitat parameters in both zones, one apparent conclusion is that aquatic snails including hosts of important parasites can tolerate wide variations in their habitat. Therefore, based on these results, it has not been possible to identify a single environmental factor that is a major determinant of host snail population dynamics. Single parameters explained on average a maximum amount of $25 \%$ (min-max, 17-48\%) of the difference in occurrence of the snail species (Table 3). Analysis of various factor combinations yielding an explanatory potential of maximally $50 \%$ indicate that many other factors than investigated in this study interact to condition the habitat for host snails. (Utzinger et al. 1997) and literature cited there in allude to the fact that it is difficult to isolate a single environmental factor as a major determinant for the distribution of host snails. However, in the present study, pulmonate snails in zone I seem to have similar habitat requirements with substrate type and flow velocity being important habitat conditioning parameters (Fig. 6). On the contrary, pulmonates B. globosus and $B$. pfeifferi are not influenced by the same factors in zone III (Fig. 6). Differences in ecological and climatic conditions between the zones may be responsible for this result. Zone I is a low rainfall area with mostly disconnected water bodies for most of the year. Water movement in these systems is through wave action and was found to be on average $0.01 \mathrm{~ms}^{-1}$. In zone III, a high rainfall area, the water systems are connected for most of the year with an average flow velocity of $0.03 \mathrm{~ms}^{-1}$. Flow velocity affects snail movement and dissipation of snail food (Boelee and Laamrani 2004). Some researchers (Appleton 1978) suggested an upper limit for snail prevalence of $0.3 \mathrm{~ms}^{-1}$ which is above the flow regime for the study sites. Heavy metal Co is positively correlated with B. pfeifferi snails in zone III. Although many metals are known to be nutrients for aquatic organisms at low concentration (Léopold et al. 2015), $\mathrm{Pb}$ and $\mathrm{Cd}$ have no known biological function and are generally toxic to most organisms (Allah et al. 1997). The positive correlation observed in this study could be as a result of the indirect effects of metals on snails through negatively impacting on the snail parasites and predators. Parasites, like predators, may have a regulatory effect on the snails (Brown et al. 1988; Loker et al. 1981). In a study of populations of two closely related pulmonate snails Physella columbiana and Lymnaea palustris, it was found that heavy metal pollution had a direct negative effect on parasites that resulted in an indirect positive effect on snails (Lefcort et al. 2002). While metals can result in reduced growth rate, reproduction and survival (Allah et al. 1997; Factor and de Chavez 2012) in snail hosts, it is hypothesized in the present study that metals could have had a more depressing effect on snail parasites and/or predators.

Seasonal variations

Although population numbers were not rigorously estimated, it was observed that all of the species of medical and veterinary importance exhibited a seasonal trend (Fig. 5). Snail distribution follows a rhythm in response to seasonal climatic variations (Phiri et al. 2007). 
Temperature and rainfall are important climatic determinants of snail populations (Appleton 1978). In the present study, both Schistosoma host snail populations tended to peak around the hot dry season (August to November). Similar results were observed in Zimbabwe (Woolhouse 1992) for B. pfeifferi. A lot of B. globosus juveniles were observed during this period unlike for $B$. pfeifferi where mostly juveniles were recorded throughout the study period. Other studies indicate the role of temperature on growth rate, reproductive success (ElEmam and Madsen 1982; Woolhouse and Chandiwana 1989) and survival (McCreesh and Booth 2014). Water flow velocity is a seasonal factor regulated by rainfall in Zambia. Impact of rain on stream hydrology and consequent flow velocity and snail prevalence have been observed in Kenya (Teesdale 1962), Tanzania (Marti and Tanner 1988) and Zimbabwe (Woolhouse and Chandiwana 1990; Woolhouse 1992).

\section{Conclusions}

The aim of this study was to provide baseline data on human and environmental factors that influence the prevalence and population dynamics of Schistosoma host snails vis-a-vis schistosomiasis transmission in two ecologically distinct zones in Zambia. The focus was twofold covering the social and the physicochemical aspects of host snail population dynamics. We have established from this study firstly that, like in many other studies, rural livelihoods have an impact on the patterning of exposure to schistosomiasis disease. While adhering to the general dynamics of schistosomiasis transmission through domestic, occupational and recreational activities, the study has shown local-level heterogeneities mediated by culture. Cassava processing and cattle herding are culturally determined exposure patterns that vary between the two zones. Second is that, although physicochemical parameters including heavy metals, water flow velocity, type of substrate and condition of water seem to have a significant influence, no single environmental parameter is a major determinant for the distribution of host snails. Third is that climatic conditions associated with season have a profound influence on the prevalence of host snails. Therefore, to address the problem of schistosomiasis requires a delicate balance between disease epidemiology and malacology of the disease vectors. The work being reported in this study forms a baseline in generating social and malacological information which is paramount in addressing schistosomiasis in Zambia. Such information is critical in designing and focussing sustainable control programmes. It highlights habitat conditioning factors including human-water contact patterns that may influence population dynamics of host snails and hence schistosomiasis prevalence. However, the downside of this study is that combining social and environmental aspects did not allow for sufficient in-depth examination of either of these aspects. However, as a baseline study, it has highlighted areas that need further investigation such as the following:

- The breeding patterns of the host snails in these areas. This information can help in planning intervention measures.

- The effect of rainfall on the snail populations. This was not accounted for in this study due to logistical constraints.

- The relationship between pulmonate species and prosobranch $M$. tuberculata because M. tuberculata was always found not associated with pulmonate species. This would be important because there are conflicting results from other studies (Giovanelli et al. 2005b; Mkoji et al. 1992; Ndifon and Ukoli 1989; Pointier et al. 1991) regarding the predatory and competitive nature of M. tuberculata.

Open Access This article is distributed under the terms of the Creative Commons Attribution 4.0 International License (http:// creativecommons.org/licenses/by/4.0/), which permits unrestricted use, distribution, and reproduction in any medium, provided you give appropriate credit to the original author(s) and the source, provide a link to the Creative Commons license, and indicate if changes were made.

\section{References}

Agnew-Blais, J., Carnevale, J., Gropper, A., Shilika, E., Bail, R., \& Ngoma, M. (2010). Schistosomiasis haematobium prevalence and risk factors in a school-age population of periurban Lusaka, Zambia. Journal of Tropical Pediatrics, 56, 247-253. doi:10.1093/tropej/fmp106.

Ahmad, S. S., Aziz, N., Butt, A., Shabbir, R., \& Erum, S. (2015). Spatio-temporal surveillance of water based infectious disease (malaria) in Rawalpindi, Pakistan using geostatistical modeling techniques. Environmental Monitoring and Assessment, 187, 1-15.

Allah, A. A., Wanas, M., \& Thompson, S. (1997). Effects of heavy metals on survival and growth of Biomphalaria glabrata Say (Gastropoda: Pulmonata) and interaction with Schistosome infection. Journal of Molluscan Studies, 63, 79-86. 
APHA. (1995). Standard methods for examination of water and wastewater (19th ed.). Washington: American Public Health Association.

Appleton, C. (1978). Review of literature on abiotic factors influencing the distribution and life cycles of bilharziasis intermediate host snails. Malacological Review, 11, 1-25.

Boelee, E., \& Laamrani, H. (2004). Environmental control of schistosomiasis through community participation in a Moroccan oasis. Tropical Medicine \& International Health, 9, 997-1004.

Boelee, E., \& Madsen, H. (2006). Irrigation and schistosomiasis in Africa: ecological aspects. Sri Lanka: International Water Management Institute. Colombo.

Brooker, S. (2007). Spatial epidemiology of human schistosomiasis in Africa: risk models, transmission dynamics and control. Transactions of the Royal Society of Tropical Medicine and Hygiene, 101, 1-8.

Brown, K. M., Leathers, B. K. and Minchella, D. J. (1988). Trematode prevalence and the population dynamics of freshwater pond snails. American Midland Naturalist, 120, 289301.

Chandiwana, S., \& Woolhouse, M. (1991). Heterogeneities in water contact patterns and the epidemiology of Schistosoma haematobium. Parasitology, 103, 363-370.

Chitsulo, L., Engels, D., Montresor, A., \& Savioli, L. (2000). The global status of schistosomiasis and its control. Acta Tropica, $77,41-51$.

Cook, C. D. (2004). Aquatic and wetland plants of Southern Africa.

Domenici, P., Claireaux, G., \& McKenzie, D. J. (2007). Environmental constraints upon locomotion and predatorprey interactions in aquatic organisms: an introduction. Philosophical Transactions of the Royal Society, B: Biological Sciences, 362, 1929-1936.

El-Emam, M. A., \& Madsen, H. (1982). The effect of temperature, darkness, starvation and various food types on growth, survival and reproduction of Helisoma duryi. Biomphalaria alexandrina and Bulinus truncatus (Gastropoda: Planorbidae), 88, 265-275. doi:10.1007/bf00008506.

Factor, C. J. B., \& de Chavez, E. R. C. (2012). Toxicity of arsenic, aluminum, chromium and nickel to the embryos of the freshwater snail, Radix quadrasi von Möellendorf 1898. Philippine Journal of Science, 141, 207-216.

Fenwick, A., Rollinson, D., \& Southgate, V. (2006). Implementation of human schistosomiasis control: challenges and prospects. Advances in Parasitology, 61, 567622.

Gazzinelli, A., Velasquez-Melendez, G., Crawford, S. B., LoVerde, P. T., Correa-Oliveira, R., \& Kloos, H. (2006). Socioeconomic determinants of schistosomiasis in a poor rural area in Brazil. Acta Tropica, 99, 260-271.

Gerber, A., Cilliers, C. J., van Ginkel, C., \& Glen, R. (2004). Aquatic plants: a guide for the identification of water plants in and around South African impoundments. South Africa: Pretoria.

Giddings, E. M., Hornberger, M. I. and Hardley, H. K. (2001). Trace Metal Concentrations in Sediment and Water and Health of Aquatic Microinvertebrate Communities of Near Park City. Summit County. Utah. U.S. Geological Survey Water Resources Investigations Report 01-4213. Salt Lake City, UT, p. 34.
Giovanelli, A., Silva, C. L. P. A. C., Leal, G. B. E., \& Baptista, D. F. (2005a). Habitat preference of freshwater snails in relation to environmental factors and the presence of the competitor snail Melanoides tuberculatus (Müller, 1774). Memórias do Instituto Oswaldo Cruz, 100, 169-176.

Giovanelli, A., Vieira, M. V., \& da Silva, C. L. C. (2005b). Interaction between the intermediate host of schistosomiasis in Brazil, Biomphalaria glabrata (Say, 1818) and a possible competitor, Melanoides tuberculata (Müller, 1774): a field study. Journal of Molluscan Studies, 71, 7-13.

Huang, Y., \& Manderson, L. (1992). Schistosomiasis and the social patterning of infection. Acta Tropica, 51, 175-194.

Kabatereine, N. B., Fleming, F. M., Nyandindi, U., Mwanza, J. C. L., \& Blair, L. (2006). The control of schistosomiasis and soil-transmitted helminths in East Africa. Trends in Parasitology, 22, 332-339. doi:10.1016/j.pt.2006.05.001.

Kapito-Tembo, A. P., Mwapasa, V., Meshnick, S. R., Samanyika, Y., Banda, D., Bowie, C., \& Radke, S. (2009). Prevalence distribution and risk factors for Schistosoma hematobium infection among school children in Blantyre, Malawi. PLoS Neglected Tropical Diseases, 3, e361.

King, C. H., \& Dangerfield-Cha, M. (2008). The unacknowledged impact of chronic schistosomiasis. Chronic Illness, 4, 65-79.

Kristensen, T. K., Malone, J. B., \& McCarroll, J. C. (2001). Use of satellite remote sensing and geographic information systems to model the distribution and abundance of snail intermediate hosts in Africa: a preliminary model for Biomphalaria pfeifferi in Ethiopia. Acta Tropica, 79, 73-78. doi:10.1016/ S0001-706X(01)00104-8.

Lefcort, H., Aguon, M., Bond, K., Chapman, K., Chaquette, R., Clark, J., Kornachuk, P., Lang, B., \& Martin, J. (2002). Indirect effects of heavy metals on parasites may cause shifts in snail species compositions. Archives of Environmental Contamination and Toxicology, 43, 34-41.

Léopold, E. N., Jung, M. C., \& Emmanuel, E. G. (2015). Accumulation of metals in three fish species from the Yaounde Municipal Lake in Cameroon. Environmental Monitoring and Assessment, 187, 1-12.

Liang, S., Seto, E. Y. W., Remais, J. V., Zhong, B., Yang, C., Hubbard, A., Davis, G. M., Gu, X., Qiu, D., \& Spear, R. C. (2007). Environmental effects on parasitic disease transmission exemplified by schistosomiasis in western China. Proceedings of the National Academy of Sciences, 104, 7110-7115. doi:10.1073/pnas.0701878104.

Loker, E., Moyo, H., \& Gardner, S. L. (1981). Trematode-gastropod associations in nine non-lacustrine habitats in the Mwanza region of Tanzania. Parasitology, 83, 381-399.

MAFF. (2001). Ministry of Agriculture, Fisheries and Food. Agricultural Commercialization Programme (ACP). 20022005. Republic of Zambia.

Mandahl-Barth, G. (1962). Key to the identification of East and Central African freshwater snails of medical and veterinary importance. Bulletin of the World Health Organization, 27, $135-150$.

Marti, H., \& Tanner, M. (1988). Field observations on the influence of low water velocities on drifting of Bulinus globosus. Hydrobiologia, 157, 119-123.

McCreesh, N., \& Booth, M. (2014). The effect of simulating different intermediate host snail species on the link between water temperature and schistosomiasis risk. PloS One, 9, e87892. 
Michael, E., Spear, R., \& Remais, J. (2010). Modelling environmentally-mediated infectious diseases of humans: transmission dynamics of Schistosomiasis in China. In Modelling parasite transmission and control, Vol. 673 (pp. 79-98). New York: Springer.

Michelson, E. (1989). Schistosomiasis in Zambia: an historical overview and review of the literature. African Journal of Medicine and Medical Sciences, 18, 269-281.

Mkoji, G., Mungai, B., Koech, D., Hofkin, B., Loker, E., Kihara, J., \& Kageni, F. (1992). Does the snail Melanoides tuberculata have a role in biological control of Biomphalaria pfeifferi and other medically important African pulmonates? Annals of Tropical Medicine and Parasitology, 86, 201.

Monde, C., Syampungani, S., \& van den Brink, P. (2015). Exploring the potential of host-environment relationship in the control of schistosomiasis in Africa. African Journal of Aquatic Science, 40, 47-55.

Mudenda, G. H., Lulemba, G., Maembe, E., Mubanga, B., Mulenga, V., \& Sinkala, G. (2005). Intensification and commercialization of aquaculture in Zambia in ASP areas.

Ndambo, N. E. M. (2005). Political Power of Small-Scale Farmers and the Role of Farmer Organisations. In T. Huvio, J. Kola and T. Lundstrom (Eds.), Small-Scale Farmers in Liberalised Trade Environment, proceedings of a Seminar (pp. 239). Haikkoo: Finland.

Ndifon, G., \& Ukoli, F. (1989). Ecology of freshwater snails in south-western Nigeria. I: distribution and habitat preferences. Hydrobiologia, 171, 231-253.

Ojewole, J. A. O. (2004). Indeginous Plants and Schistosomiasis Control in South Africa: Molluscicidal Activity of Some Zulu Medicinal Plants. Boletin Latinoamericano y del Carib de Plantas Medicinales y Aromaticas, 3, 1.

Patz, J. A., Graczyk, T. K., Geller, N., \& Vittor, A. Y. (2000). Effects of environmental change on emerging parasitic diseases. International Journal for Parasitology, 30, 13951405 .

Payne, R. W. (2007). GenStat for Windows (Release 10) Reference. Manual, Part 3, Procedure Library PL18. Hemel: VSN International.

Phiri, A. M., Phiri, I. K., Chota, A., \& Monrad, J. (2007). Trematode infections in freshwater snails and cattle from the Kafue wetlands of Zambia during a period of highest cattle-water contact. Journal of Helminthology, 81, 85-92. doi:10.1017/S0022149X07387786.

Pointier, J.-P., Balzan, C., Chrosciechowski, P., \& Incani, R. N. (1991). Limiting factors in biological control of the snail intermediate hosts of Schistosoma mansoni in Venezuela. Journal of Medical and Applied Malacology, 3, 53-67.

Sady, H., Al-Mekhlafi, H. M., Mahdy, M. A., Lim, Y. A., Mahmud, R., \& Surin, J. (2013). Prevalence and associated factors of schistosomiasis among children in Yemen: implications for an effective control programme. Plos Neglected Tropical Diseases, 7, e2377.

Satayathum, S. A., Muchiri, E. M., Ouma, J. H., Whalen, C. C., \& King, C. H. (2006). Factors affecting infection or reinfection with Schistosoma haematobium in coastal Kenya: survival analysis during a nine-year, school-based treatment program. The American Journal of Tropical Medicine and Hygiene, $75,83-92$.

Simoonga, C., Utzinger, J., Brooker, S., Vounatsou, P., Appleton, C., Stensgaard, A.-S., Olsen, A., \& Kristensen, T. K. (2009).
Remote sensing, geographical information system and spatial analysis for schistosomiasis epidemiology and ecology in Africa. Parasitology, 136, 1683-1693.

Siziya, S., \& Mushanga, M. (1996). Importance of schistosomiasis in the Isoka district of Zambia: a prerequisite for its control using community participation. Social Science and Medicine, 42, 431-435. doi:10.1016/0277-9536(95)00147-6.

Sow, S., de Vlas, S. J., Stelma, F., Vereecken, K., Gryseels, B., \& Polman, K. (2011). The contribution of water contact behavior to the high Schistosoma mansoni Infection rates observed in the Senegal River Basin. BMC Infectious Diseases, 11, 198.

Strahan, R., Chiyesu, K. o., \& Schneider-Kolsky, M. E. (2012). Ultrasound study of liver disease caused by Schistosoma mansoni in rural Zambian schoolchildren. Journal of Medical Imaging and Radiation Oncology, 56, 390-397. doi:10.1111/j.1754-9485.2012.02371.x.

Teesdale, C. (1962). Ecological observations on the molluscs of significance in the transmission of bilharziasis in Kenya. Bulletin of the World Health Organization, 27, 759.

Ter Braak, C. J. F., \& Šmilauer, P. (2012). Canoco reference manual and user's guide: software for ordination, version 5.0. Ithaca: Microcomputer Power.

Utzinger, J., Mayombana, C., Mez, K., \& Tanner, M. (1997). Evaluation of chemical and physical-morphological factors as potential determinants of Biomphalaria pfeifferi (Krauss, 1848) distribution. Memórias do Instituto Oswaldo Cruz, 92, 323-328.

Vora, N. (2008). Impact of anthropogenic environmental alterations on vector-borne diseases. The Medscape Journal of Medicine, 10, 238.

WHO. (1998). Report of the WHO Informal Consultation on Schistosomiasis Control. WHO/CDS/CPC/SIP/99.2. Geneva: World Health Organization.

Woolhouse, M. E. J. (1992). Population biology of the freshwater snail Biomphalaria pfeifferi in the Zimbabwe Highveld. Journal of Applied Ecology, 29, 687-694. doi:10.2307/ 2404477.

Woolhouse, M., \& Chandiwana, S. (1989). Spatial and temporal heterogeneity in the population dynamics of Bulinus globosus and Biomphalaria pfeifferi and in the epidemiology of their infection with schistosomes. Parasitology, 98, 21-34.

Woolhouse, M. \& Chandiwana, S. (1990). Population biology of the freshwater snail Bulinus globosus in the Zimbabwe highveld. Journal of Applied Ecology, 27, 41-59.

Ximenes, R., Southgate, B., Smith, P. G., \& Guimarães Neto, L. (2003). Socioeconomic determinants of schistosomiasis in an urban area in the Northeast of Brazil. Revista Panamericana de Salud Pública, 14, 409-421.

Yang, K., Zhou, X.-N., Jia, T.-W., Yang, G.-J., Wu, X.-H., Shi, X.-W., Li, H.-J., Steinmann, P., Utzinger, J., Bergquist, R. (2015). Eco-social determinants of Schistosoma japonicum infection supported by multi-level modelling in Eryuan county, People's Republic of China. Acta Tropica, 141, 391-398.

Yi-Xin, H., \& Manderson, L. (2005). The social and economic context and determinants of schistosomiasis japonica. Acta Tropica, 96, 223-231. doi:10.1016/j.actatropica.2005.07.015.

ZBCP. (2009). Baseline survey for Schistosomiasis and soiltransmitted Helminthiasis. In Book; Baseline survey for Schistosomiasis and soil_transmitted Helminthiasis. Zambia Bilharzia Control Programme. 
Zhang, Z., Ward, M., Gao, J., Wang, Z., Yao, B., Zhang, T., \& Jiang, Q. (2013). Remote sensing and disease control in China: past, present and future. Parasites \& Vectors, 6, 11.
Zhou, X. N., Malone, J. B., Kristensen, T. K., \& Bergquist, N. R. (2001). Application of geographic information systems and remote sensing to schistosomiasis control in China. Acta Tropica, 79, 97-106. doi:10.1016/S0001-706X(01)00107-3. 